\title{
Fetal growth pattern is regulated sex-specific dependent on maternal BMI
}

\author{
B Brune*, D Naehter, T Brune \\ From 50th Workshop for Pediatric Research \\ Gottingen, Germany. 20-21 March 2014
}

\begin{abstract}
Aims
In previous studies we could show that male neonates with a Body Mass Index (BMI) $<10 \mathrm{P}$ have a double risk to develop obesity during the first 6 years of life compared to females. As the main factor of influence for developing obesity we could identify the maternal BMI for both male and female infants. This leads to the hypothesis that maternal overweight has a sex specific influence on the intrauterine fetal growth pattern (Brune et al: Obesity 2010, 4:798-802).
\end{abstract}

\section{Methods}

202 full-term infants (101 $\mathrm{O}^{\prime /} / 101$ Q) and 206 premature infants $(109$ ơ/ 97 \%) were included into the study. To compare the data, birth weight and length of the full-term infants were adjusted to $36 \mathrm{GA}$ (gestational age) and of premature infants to 30 GA using Prader Percentiles. After delivery, the premature infants received a standard nutrition and 6 weeks later weight and length were measured again. For all children the Ponderal Indices (PI) were calculated. Univariate covariance analysis was performed using PI as target size, sex or GA as fixed factors and maternal BMI before pregnancy as a covariate. We investigated whether there was a difference between interactions of PI depending on maternal BMI and children's sex in full-term infants at the time of $36 \mathrm{GA}$ and in premature infants both at $30 \mathrm{GA}$ and at $36 \mathrm{GA}$.

\section{Results}

The PI of female full-term infants correlated positively, that of male negatively with maternal BMI. There was no sex difference between premature infants at the time of delivery $(\mathrm{p}=0.2)$, but after receiving a standard nutrition during 6 weeks the correlation of PI with maternal BMI

University Children's Hospital Magdeburg, Magdeburg, Germany appeared significantly vice versa compared to full-term infants $(\mathrm{p}=0.01)$.

\section{Conclusion}

Our results show that maternal overweight influences intrauterine growth pattern and therefore fetal programming sex-specific during the last 6 weeks of gestation.

Published: 11 September 2014

doi:10.1186/2194-7791-1-S1-A5

Cite this article as: Brune et al:: Fetal growth pattern is regulated sexspecific dependent on maternal BMI. Molecular and Cellular Pediatrics 2014 1(Suppl 1):A5.
Submit your manuscript to a SpringerOpen ${ }^{\bullet}$ journal and benefit from:

- Convenient online submission

- Rigorous peer review

- Immediate publication on acceptance

- Open access: articles freely available online

- High visibility within the field

Retaining the copyright to your article

Submit your next manuscript at $>$ springeropen.com
(C) 2014 Brune et al; licensee Springer This is an Open Access article distributed under the terms of the Creative Commons Attribution License (http://creativecommons.org/licenses/by/2.0), which permits unrestricted use, distribution, and reproduction in any medium, provided the original work is properly cited. 